\title{
The Role of Scintigraphy in Confirmation of Suspected Brain Death
}

\author{
Prashant Jolepalem and Helena R. Balon \\ Department of Diagnostic Radiology and Molecular Imaging, Oakland University William Beaumont School of Medicine and \\ Beaumont Health System, Royal Oak, Michigan
}

\begin{abstract}
We present a case illustrating how cerebral perfusion scintigraphy can be used to assist in crucial medical decision making in the intensive care setting for patients who are maintained on life support but are clinically suspected to have brain death. Cerebral perfusion scintigraphy can confirm brain death but cannot be used to diagnose it. ${ }^{99 \mathrm{mTC}} \mathrm{TM}$-HPO and ${ }^{99 \mathrm{mT}} \mathrm{Tc}$-ethylcysteinate dimer are the preferred imaging agents since they cross the blood-brain barrier.
\end{abstract}

Key Words: neurology; pediatrics; SPECT; brain death; cerebral perfusion scintigraphy

J Nucl Med Technol 2013; 41:306-307

DOI: 10.2967/jnmt.113.127639

$\mathbf{T}$ his case report illustrates how cerebral perfusion scintigraphy can be used to assist in crucial medical decision making in the intensive care setting for patients who are maintained on life support but are clinically suspected to have brain death. The choice of radiotracers, imaging findings, and appropriate-use criteria will be discussed. The residents' familiarity with interpretation criteria is critical, as these studies may have to be performed at any time of the day or night, and usually in an emotionally stressful situation.

\section{CASE REPORT}

A 3-y-old girl with a history of congenital adrenal hyperplasia presented with status epilepticus, hypoglycemia, and acute respiratory failure requiring mechanical ventilation after she had been found unresponsive by her parents. CT scanning on admission (Fig. 1) showed diffuse cerebral edema and loss of gray matter-white matter differentiation. Subsequent brain MR perfusion imaging (Fig. 2) demonstrated decreased perfusion in the thalami and basal ganglia and diffusely decreased perfusion in the cerebral cortex. MR spectroscopy demonstrated diffusely decreased $\mathrm{N}$-acetylaspartic acid, indicating decreased neuronal activ-

Received Jun. 18, 2013; revision accepted Aug. 8, 2013.

For correspondence or reprints contact: Prashant Jolepalem, 3601 W. 13

Mile Rd., Royal Oak, MI 48073.

E-mail: pjolepalem@gmail.com

Published online Oct. 24, 2013.

COPYRIGHT @ 2013 by the Society of Nuclear Medicine and Molecular Imaging, Inc. ity; elevation of choline, indicating increased cell turnover; and the presence of lactate, indicating hypoxia (1). These findings were compatible with hypoxic brain injury. Follow-up CT performed $2 \mathrm{~d}$ later demonstrated impending transtentorial herniation (Fig. 3). Despite several interventions, the patient eventually showed no brain stem reflexes and had an isoelectric electroencephalogram. A scintigraphic cerebral perfusion study was ordered to confirm brain death before preparing for organ donation and discontinuation of life support. SPECT images of the head were obtained $20 \mathrm{~min}$ after intravenous injection of $407 \mathrm{MBq}(11 \mathrm{mCi})$ of ${ }^{99 \mathrm{~m}} \mathrm{Tc}-$ hexamethylpropyleneamine oxime (HMPAO). The images did not demonstrate any evidence of cerebral perfusion, whereas radiotracer activity was seen in the scalp, lacrimal glands, and salivary glands (Fig. 4). The patient was subsequently declared deceased.

\section{DISCUSSION}

Cerebral perfusion scintigraphy is a simple, noninvasive method to confirm, but not diagnose, brain death (2). Before proceeding with the study, the patient should meet the criteria for the clinical diagnosis of brain death, which are as follows (3):

- The patient must be in a deep coma with total absence of brain stem reflexes and spontaneous respiration.

- Potentially reversible causes (drug intoxication, metabolic derangement, hypothermia) must be excluded.

- The cause of the brain dysfunction must be diagnosed.

- Clinical findings of brain death must be present for a defined period of observation (usually 6-24 h).

Radionuclide techniques do not require the withdrawal of medical therapy and are especially useful in the settings of hypothermia, drug overdose, shock, or an inconclusive physical examination $(2,4)$. This study is often a critical and decisive step for the patient's family to give their consent to withdraw care and harvest organs.

The increased intracranial pressure caused by necrosis, edema, and autolysis of the brain tissue impedes intracranial perfusion (4), thus making the brain death scan highly specific. For a study to be considered positive, there must be no perfusion to the brain. Expected activity can be seen in the scalp or projecting over the nose (known as 


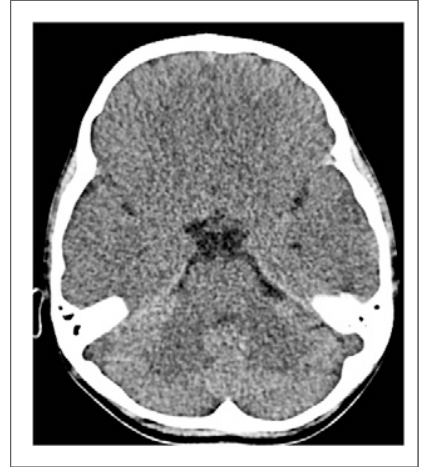

FIGURE 1. Non-contrastenhanced CT scan showing diffuse cerebral edema, bilateral sulcal effacement, and loss of gray matterwhite matter differentiation. Occipital lobe is spared.

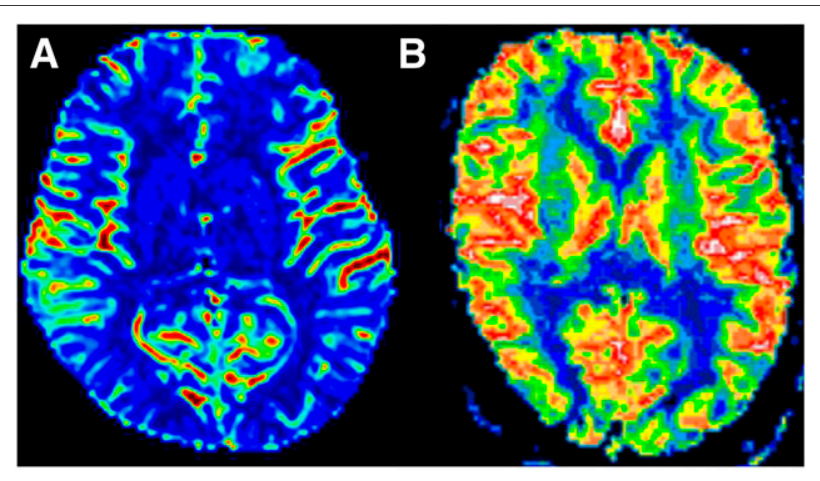

FIGURE 2. (A) Regional cerebral blood flow MR perfusion study showing diffusely decreased perfusion to basal ganglia and thalami and mild reduction in cerebral cortex. (B) Cerebral perfusion study with normal findings is shown for comparison. (Courtesy of Department of MR Physics, Lund University, Lund, Sweden.)

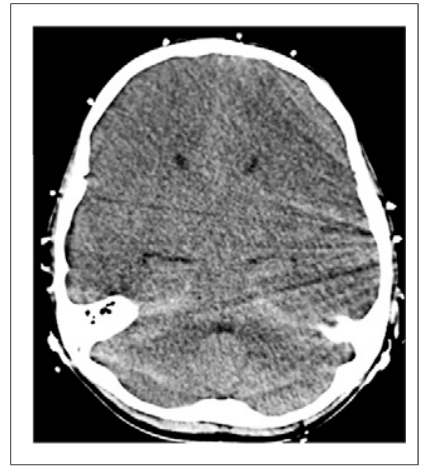

FIGURE 3. Follow-up CT scan showing progressive diffuse cerebral edema and interval development of basal cistern effacement. These findings were compatible with impending transtentorial herniation.

the hot-nose sign) due to shunting of carotid blood flow to the maxillary branches $(4,5)$.

${ }^{99 \mathrm{~m}}$ Tc-diethylenetriminepentaacetic acid (DTPA) in a dose of $370-740 \mathrm{MBq}(10-20 \mathrm{mCi})$ can be used as an alternative radiopharmaceutical, but its use makes the study much more technically challenging because the flow images are the only diagnostic part of the study $(4,5)$. Since ${ }^{99 m}$ Tc-DTPA is water-soluble and thus does not cross the intact blood-brain barrier, interpretation is solely dependent on seeing flow within the internal carotid artery, anterior cerebral artery, and middle cerebral artery on the

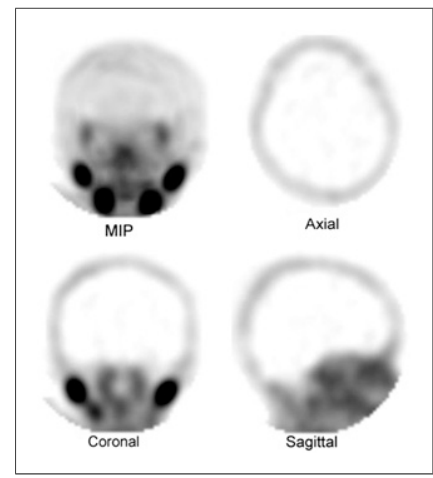

FIGURE 4. SPECT images after $99 \mathrm{mTC}$-HMPAO administration displayed as volumerendered maximum-intensity projection (MIP) and tomographic slices in 3 planes. Images demonstrate activity in scalp, lacrimal glands, and salivary glands but absence of cerebral perfusion.

anterior views of the radionuclide angiogram. Static images cannot differentiate between a normal brain and a dead brain, as there will be no intracranial activity in either. If acquisition of the radionuclide angiogram is unsuccessful, a repeated study becomes necessary. Fortunately, imaging can be repeated at a short interval because of rapid renal excretion of $99 \mathrm{~m}$ Tc-DTPA.

In most institutions, brain-specific agents such as ${ }^{99 \mathrm{~m}} \mathrm{Tc}-$ HMPAO or ${ }^{99 \mathrm{~m} T c-e t h y l c y s t e i n a t e ~ d i m e r ~ a r e ~ p r e f e r r e d, ~ a s ~}$ they are lipid-soluble and thus cross the blood-brain barrier and enter normally perfused cerebral tissue. Thus, use of these radiopharmaceuticals makes dynamic imaging a noncritical step in image acquisition $(2,4,5)$. Additionally, they allow for imaging with suboptimal patient positioning, which is often the case because of the presence of life support equipment. The use of SPECT, when feasible, makes image interpretation even more straightforward.

\section{CONCLUSION}

Cerebral perfusion scintigraphy can be used to confirm, but not diagnose, clinically suspected brain death. ${ }^{99 \mathrm{~m}} \mathrm{Tc}-$ HMPAO and ${ }^{99 \mathrm{~m}}$ Tc-ethylcysteinate dimer are the preferred imaging agents since they cross the blood-brain barrier.

\section{DISCLOSURE}

No potential conflict of interest relevant to this article was reported.

\section{REFERENCES}

1. Ross BD, Colletti P, Lin A. MR spectroscopy of the brain: neurospectroscopy. In: Edelman RR, Hesselink JR, Zlatkin MB, Crues JV, eds. Clinical Magnetic Resonance Imaging. 3rd ed. Philadelphia, PA: Saunders-Elsevier; 2006:18401910.

2. Donohoe KJ, Agrawal G, Frey KA, et al. SNM practice guideline for brain death scintigraphy 2.0. J Nucl Med Technol. 2012;40:198-203.

3. Wijdicks EFM, Varelas PN, Gronseth GS, Greer DM. Evidence-based guideline update: determining brain death in adults: report of the Quality Standards Subcommittee of the American Academy of Neurology. Neurology. 2010;74:19111918.

4. Ziessman HA, O'Malley JP, Thrall JH. Nuclear Medicine (The Requisites in Radiology). 3rd ed. Philadelphia, PA: Mosby; 2006:427f-430f, 435-438.

5. Mettler FA, Guiberteau MJ. Essentials of Nuclear Medicine. 6th ed. Philadelphia, PA: Elsevier Inc.; 2012:75-78. 